\title{
Weekly variation in diet and physical activity among 4-75-year-old Danes
}

\author{
Matilda Nordman ${ }^{1,2, *} \odot$, Jeppe Matthiessen², Anja Biltoft-Jensen², Christian Ritz ${ }^{1}$ and \\ Mads F Hiorth ${ }^{1}$ \\ 'Department of Nutrition, Exercise and Sports, Faculty of Science, University of Copenhagen, Frederiksberg, Denmark: \\ 2Division of Risk Assessment and Nutrition, National Food Institute, Technical University of Denmark, Kemitorvet \\ Building 201, 2800 Kongens Lyngby, Denmark
}

Submitted 21 March 2019: Final revision received 7 August 2019: Accepted 19 August 2019: First published online 18 February 2020

\begin{abstract}
Objective: To compare dietary intake and physical activity (PA) between days of the week in a large sample of the Danish population; furthermore, to investigate the influence of gender and age as determinants for weekly variation.

Design: Analysis was based on cross-sectional data from the Danish National Survey of Diet and Physical Activity 2011-2013. Dietary intake and PA were assessed by $7 \mathrm{~d}$ of pre-coded food diaries and pedometer-determined step counts. Dietary intake and PA on weekdays (Monday-Thursday), Friday, and weekend days (Saturday and Sunday) were compared using linear mixed models.

Setting: Survey with national representation, conducted in Denmark between 2011 and 2013.

Participants: A random sample of 4-75-year-old Danes, $n 3934$ and $n 3530$ in analysis of dietary intake and PA, respectively.

Results: Energy intake during Friday and weekend days was 7-20\% higher compared with weekdays, while step counts were 10 and $17 \%$ lower on Saturday and Sunday, respectively (all $P<0 \cdot 001$ ). Energy density of liquids and solids, consumption of added sugar, alcohol, discretionary foods, beer, wine and sugar-sweetened beverages were substantially higher, and consumption of dietary fibre, vegetables, fruit and wholegrain products were lower, during Friday and weekend days compared with weekdays (all $P<0 \cdot 001$ ). The observed patterns were present across gender and age, although weekly variation was most pronounced among children and relatively modest among the elderly.

Conclusions: Weekend health behaviours of Danes display less favourable eating and PA behaviour compared with weekdays, making the weekend an important target for public health interventions aiming to improve dietary intake and PA behaviour.
\end{abstract}

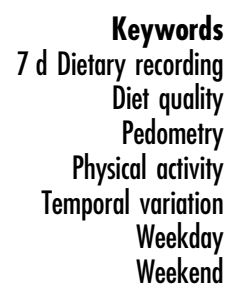

In the past few decades, the prevalence of overweight and obesity has increased drastically in most countries of the world $^{(1)}$ and nearly $60 \%$ of the European adult population is currently overweight or obese ${ }^{(2)}$. Overweight and obesity are associated with several adverse health consequences and an increased risk of non-communicable diseases, such as CVD, diabetes, musculoskeletal disorders and certain cancers ${ }^{(3)}$. With the substantial societal as well as personal cost of poor health caused by obesity and related comorbidities, there is an evident need to address the issue.

A balanced, healthy diet and sufficient physical activity (PA) are key factors in the prevention of overweight and several chronic diseases, and are the cornerstones of health promotion. As in most of the Western world, the diet of the Danish population exhibits inadequate intakes of dietary fibre, fruit and vegetables, while intakes of saturated fat, added sugar, salt and alcohol exceed recommendations ${ }^{(4)}$. Several of these dietary patterns have been associated with adverse health effects, such as increased adiposity, type 2 diabetes and $\mathrm{CVD}^{(5-8)}$. Furthermore, average PA levels are below recommendations ${ }^{(9,10)}$. While much research has focused on identification of the above-mentioned behavioural patterns, less attention has been paid to temporal variation of dietary intake and PA. 
Weekly variation patterns have previously been observed in health behaviours such as sleep duration and sedentary time ${ }^{(11)}$, dietary intake ${ }^{(12-18)}$ and $\mathrm{PA}^{(11,19-24)}$ in various populations. In the short term such patterns have been observed to affect health markers, such as fasting insulin and $\mathrm{TAG}^{(25,26)}$, and in the long term could have potential consequences for body weight and health status ${ }^{(27,28)}$. Characterization of food consumption and PA across the days of the week can help target health promotion initiatives striving to improve dietary intake and PA behaviour of the population.

Therefore, the aim of the present study was to compare dietary intake and PA between days of the week, while investigating the potential influence of age and gender, using a large sample of the Danish population having $7 \mathrm{~d}$ of dietary recordings and pedometer monitoring. We hypothesized that individuals would display less healthy behaviour during weekends compared with weekdays, and furthermore that this difference would be more pronounced among children and less so among the elderly, as previously indicated for weekly variation in blood markers in a Danish population ${ }^{(26)}$.

\section{Methods}

Data were derived from the Danish National Survey of Diet and Physical Activity (DANSDA) 2011-2013; a nationwide, cross-sectional survey assessing diet and PA of the Danish population $^{(4,29)}$. For DANSDA 2011-2013, a representative sample of 7356 adults and children aged 4-75 years was randomly drawn from the Danish Civil Registration System $^{(30)}$ and data collection took place between April 2011 and August 2013. Danish citizenship was a criterion for inclusion; however, disabled individuals, residents of nursing homes and home-dwelling individuals receiving meals from outside the home were excluded from the sample to ensure that individuals have sufficient knowledge about their dietary intake.

Dietary intake was estimated by $7 \mathrm{~d}$ consecutive dietary recording, using food diaries with pre-coded response categories and open answer options. The starting day of recording could be any weekday; however, due to participant preferences, Monday and Tuesday were over-represented while Saturday and Sunday were under-represented. The dietary record was structured according to the typical Danish meal pattern (i.e. breakfast, lunch, dinner and in-between meals) and food items were categorized according to food groups. The pre-coded response options included food items and beverages most commonly consumed in Denmark, with the possibility of adding additional items in an open field. Portion sizes were estimated by predefined household measures (cups, glasses, spoons, slices, etc.) and portion-size pictures. For each participant, the intakes of different food items, and the content of energy and nutrients within, were estimated using the General Intake Estimation System (GIES) software version 1.000.i6 and the Danish Food Composition Databank version 7.0 (www.foodcomp.dk), both developed at the National Food Institute of the Technical University of Denmark. Validation studies of the $7 \mathrm{~d}$ pre-coded dietary record used in DANSDA have been carried out in populations of Danish adults and children ${ }^{(31-33)}$. Compared with a $4 \mathrm{~d}$ weighed food record, estimated mean intakes of nutrients and foods were generally consistent with the pre-coded food diary ${ }^{(31)}$; and compared with objectively measured energy expenditure, energy intake was underreported by $12 \%$ in adults aged $20-59$ years and by 7 and $20 \%$ in children aged $7-8$ and $12-13$ years, respectively ${ }^{(32,33)}$. Misreporters of dietary intake in the present study were identified by evaluating reported energy intake against presumed energy requirement, using the Goldberg cut-offs for the ratio between reported energy intake and estimated BMR at the individual level as suggested by Black ${ }^{(34,35)}$, assuming a moderate physical activity level for all individuals (corresponding to 1.8 for children aged $<18$ years and 1.6 for adults) ${ }^{(36)}$. BMR was estimated by age- and gender-specific Schofield equations with measured weights ${ }^{(37)}$. Individuals with at least four valid days of recording, including one weekend day (Saturday or Sunday), were included in the present analysis.

In DANSDA food items have been aggregated into food groups based on nutritional characteristics ${ }^{(4)}$, and the presently examined dietary variables include measures of energy, macronutrients, foods and beverages, providing information of diet quantity and quality. Dietary variables include intakes of energy, fruit, vegetables, fish, wholegrain products, red meat (both processed and non-processed meats from four-legged mammals), sugarsweetened beverages, beer and wine, fast food, discretionary foods, alcohol, carbohydrates, protein, fat, saturated fat, added sugar, fibre and energy density (separately for solid and liquid components of the diet). Foods, beverages and fibre intake are given relative to a $10 \mathrm{MJ}$ diet (i.e. as $\mathrm{g} / 10 \mathrm{MJ}$ ), alcohol intake is given as $\mathrm{g} / \mathrm{d}$ and the remaining macronutrients are given relative to total energy intake (E\%), excluding potential energy contribution from alcohol. The variable 'wholegrain products' was calculated from the reported intakes of ryebread, oats and coarse wheat bread, which contribute $77-80 \%$ of total wholegrain intake in Denmark ${ }^{(38)}$. The variable 'sugar-sweetened beverages' was computed as the sum of soda, non-alcoholic cider, ice teas and sugary fruit drinks. 'Discretionary foods' are defined as high-energy-density, low-nutrient-density foods that contribute a considerable amount of "empty calories', while not representing a necessary part of the diet. Both sweet and savoury foods were included, such as cakes, sweets, chocolate, sweet desserts, chocolate spreads, chips and salted nuts. Finally, 'fast food' is comprised of readily available convenience foods, often highly 
processed and energy-dense, such as pizza, burgers, fries, hot dogs, spring rolls, kebab sandwiches and sandwiches consumed between meals as snacks.

Pedometer-determined step counts were measured during the same $7 \mathrm{~d}$ monitoring period as the dietary assessment. Trained interviewers instructed participants to wear the pedometer (Yamax SW-200, Tokyo, Japan) on the hip during waking hours and to fill in step diaries. Step diaries were adapted from Tudor-Locke et $a l^{(39)}$ and included wear time and time spent cycling and doing exercise. Pedometers do not capture non-ambulatory PA, such as cycling, swimming and weight training. To give a more accurate estimate of the total volume of PA in the Danish population, a cycling-adjusted step count was estimated, as cycling is the key non-ambulatory activity in Denmark ${ }^{(29)}$. Cycling-adjusted step counts were estimated by adding 160 steps/min of cycling to the crude step count, although not exceeding an addition of 10000 steps from cycling to avoid overestimation $^{(29)}$. At least four valid days, including one weekend day (Saturday or Sunday), were required for inclusion in the analysis of $\mathrm{PA}^{(40)}$. A valid day was defined as having a pedometer wear time $\geq 10 \mathrm{~h}$ and a step count between 100 and 50000 steps $/ \mathrm{d}^{(29)}$. Average step counts for the monitoring period of $<1000$ or $>25000$ steps/d (>30000steps/d for children) were treated as outliers and excluded from analysis, as suggested by Tudor-Locke et $a l^{(41)}$, unless the high or low step count could be explained by deviating activity level in the step diary. Step counts and cycling-adjusted step counts are given both in absolute amounts (steps/d) and relative to pedometer wear time during a valid day (cadence; steps/min).

Educational level and weight status were determined by trained interviewers during baseline face-to-face interviews. Weight was measured to the nearest $0 \cdot 1 \mathrm{~kg}$ using an electronic scale (ADE BE 822; ADE Germany, Hamburg, Germany) and standing height to the nearest $0.1 \mathrm{~cm}$ using a portable stadiometer (Charder HM200P PortStad; Charder Electronic Co., Taichung City, Taiwan), with the participant's head positioned at the Frankfurt horizontal plane. Participants wore light clothing and no shoes and were encouraged to empty their bladder prior to measurement. Measurements were repeated twice and the average was reported. For adults, weight status was classified based on international BMI standards into underweight (BMI $<18.5 \mathrm{~kg} / \mathrm{m}^{2}$ ), normal weight $\quad\left(18.5 \mathrm{~kg} / \mathrm{m}^{2} \leq \mathrm{BMI}<25 \mathrm{~kg} / \mathrm{m}^{2}\right), \quad$ overweight $\left(25 \mathrm{~kg} / \mathrm{m}^{2} \leq \mathrm{BMI}<30 \mathrm{~kg} / \mathrm{m}^{2}\right)$ and obesity $\left(\mathrm{BMI} \geq 30 \mathrm{~kg} / \mathrm{m}^{2}\right)$; the corresponding classification for children was based on age- and gender-specific International Obesity Task Force BMI cut-offs ${ }^{(42)}$. Educational level was classified into six levels based on the length of the education: basic school ( $<12$ years), upper secondary school (12 years), vocational education (13 years, practical), short higher (13-14 years), medium higher ( $15-16$ years) and long higher ( $\geq 17$ years).

We divided participants into four age groups to capture the different life stages represented in the population and enable identification of differing health behaviour patterns therein: children aged 4-13 years (children under parental influence); adolescents and young adults aged 14-24 years (youth typically still undergoing education); adults aged 25-59 years (adults in family forming and parenting age); and elderly aged 60-75 years (older adults at or close to retirement age). Preliminary analysis and previous research have indicated that patterns of dietary intake and PA are rather stable through Monday to Thursday, but may follow distinct patterns on Friday, Saturday and Sunday ${ }^{(12,13,43)}$. Consequently, we constructed a four-level categorical variable with Monday, Tuesday, Wednesday and Thursday belonging to the same category (i.e. 'weekdays') and Friday, Saturday and Sunday being separate categories. For ease of reading, Saturday and Sunday are collectively referred to as 'weekend days' when appropriate.

\section{Statistical analysis}

The study population was described by means of counts and proportions and means and standard deviations.

Weekday variation in dietary and PA variables was analysed by means of linear mixed models. One model per outcome was constructed, with weekday category (Monday-Thursday, Friday, Saturday and Sunday), gender and age as fixed effects and subject as random effect. All linear mixed models were validated by inspection of residual plots, normal quantile-quantile plots of the residuals and normal quantile-quantile plots for predicted random effects. Estimated marginal means for weekday categories and corresponding $95 \%$ confidence intervals were obtained using the $\mathrm{R}$ package lsmeans version 2.27-61 ${ }^{(44)}$. Differences between weekday categories were assessed by pairwise comparisons using post hoc $t$ tests. Adjustment of $P$ values was based on the single-step method $^{(45)}$. For consumption of foods and beverages, the means are based on 'intake days' only, that is when the intake of a specific food product on an observation day was $>0$. Skewed outcome variables were transformed when appropriate by logarithmic transformation, square root transformation or Box-Cox transformation, and subsequently back transformed.

Variables representing intakes of foods and beverages typically contained large proportions of zeros and, consequently, logistic mixed-effects regression models were fitted to estimate the consumption probability (Prob.) of foods and beverages on different weekdays. Pairwise comparisons were performed on the log-odds scale, and the estimated Prob. and the corresponding 95\% confidence interval were obtained through back transformation. The logistic models contained weekday category, gender and age as fixed effects and subject as random effect.

To investigate the potential influence of gender and age as determinants for a weekly variation in dietary intake and PA, stratified analyses were performed for different age groups and for males and females separately. Finally, 
sensitivity analysis excluding under- and over-reporters of dietary intake were performed for energy intake.

Statistical significance in all pairwise comparisons was indicated by compact letter display. Significance was displayed at $P<0.001$ in main analyses and subset analyses by gender, while $P<0.01$ was used in age subsets. Data preparation and descriptive statistics were performed in the statistical software package IBM SPSS Statistics for Windows version 25 and all other statistical analyses were carried out in R statistical software version 3.3.2 ${ }^{(46)}$.

\section{Results}

The final study population represents $54.3 \%$ of the originally drawn survey sample. The reasons for loss and exclusion of participants are described in more detail in the flow diagram (see online supplementary material, Supplemental Fig. S1). A total of 3940 individuals (51.1\% female) with a mean age of 38.7 (SD 21.2) years and $47.4 \%$ being overweight or obese were included in analysis, of which $89.4 \%$ had valid recordings for both PA and dietary intake (Table 1). Details about the analytical samples are presented in Supplemental Table S1.

PA, with and without adjustment for cycling and pedometer wear time (cadence), was lower on weekend days compared with weekdays (Monday-Thursday; $P<0.001$; Table 2). Measured as steps/d, PA was 10 and $17 \%$ lower on Saturday and Sunday, respectively, compared with weekdays. No difference in PA was found between weekdays and Friday $(P>0.001)$. A decrease in PA was observed in all age groups, the weekday-weekend difference declining with each age group from the youngest to the oldest, and the patterns observed were similar for raw steps and cycling-adjusted steps (Fig. 1 and online supplementary material, Supplemental Table S2). The decrease in step count from weekdays to Saturday and Sunday, respectively, was 21 and $30 \%$ in the youngest age group (4-13 years), whereas it was only 7 and $8 \%$ in the oldest age group (60-75 years). Only minor differences in weekly variation in PA were observed between genders (Supplemental Table S2).

Overall, energy intake, energy density (solids and liquids), intakes of added sugar, discretionary foods, alcohol, and beer and wine were higher, while intakes of fruit, vegetables, fibre and wholegrain products were lower, during weekend days (Saturday and Sunday) and Friday, compared with weekdays $(P<0.001$; Table 2 and online supplementary material, Supplemental Figs S2 and S3). Only minor differences in dietary intake during the week were observed between genders (Supplemental Tables S3 and S4). Overall, the weekly variation in dietary intake appeared most pronounced for children (4-13 years) and least pronounced for the elderly (60-75 years; Figs 2 and 3, and Supplemental Tables S5 and S6), as seen for the relative increase in $\mathrm{E} \%$ of added sugar from weekdays to Saturday, which was $76 \%$ for $4-13$-year-olds, $34 \%$ for 14-24-year-olds, $29 \%$ for 25-59-year-olds and $8 \%$ for $60-75$-year-olds $(P<0.01$ for all). The same observation was made for sugar-sweetened beverages and discretionary foods. The mean intake of alcohol increased by $94 \%$ on Saturdays compared with weekdays in 16-24-yearolds, by $81 \%$ in $25-59$-year-olds and by $42 \%$ in $60-75-$ year-olds.

Table 1 Descriptive characteristics of the study population of 4-75-year-old Danes, overall and according to gender (Danish National Survey of Diet and Physical Activity 2011-2013)

\begin{tabular}{|c|c|c|c|c|c|c|}
\hline & \multicolumn{2}{|c|}{ All $(n 3940)$} & \multicolumn{2}{|c|}{ Female (n2012) } & \multicolumn{2}{|c|}{ Male $(n 1928)$} \\
\hline & Mean or $n$ & SD or $\%$ & Mean or $n$ & SD or $\%$ & Mean or $n$ & SD or $\%$ \\
\hline Age (years), mean and SD & $38 \cdot 7$ & $21 \cdot 2$ & $38 \cdot 9$ & $21 \cdot 0$ & $38 \cdot 4$ & $21 \cdot 4$ \\
\hline \multicolumn{7}{|l|}{ Age group, $n$ and $\%$} \\
\hline $4-13$ years & 693 & $17 \cdot 6$ & 340 & $16 \cdot 9$ & 352 & $18 \cdot 3$ \\
\hline $14-24$ years & 582 & $14 \cdot 8$ & 298 & $14 \cdot 8$ & 284 & 14.7 \\
\hline $25-59$ years & 1856 & $47 \cdot 1$ & 969 & $48 \cdot 2$ & 887 & $46 \cdot 0$ \\
\hline $60-75$ years & 809 & 20.5 & 405 & $20 \cdot 1$ & 404 & $21 \cdot 0$ \\
\hline \multicolumn{7}{|l|}{ Educational level ${ }^{*}$ ( $n$ 3812), $n$ and \% } \\
\hline Basic school ( $<12$ years) & 548 & 14.4 & 294 & $15 \cdot 1$ & 254 & 13.5 \\
\hline Upper secondary school (12 years) & 253 & $6 \cdot 6$ & 135 & 6.9 & 118 & $6 \cdot 3$ \\
\hline Vocational education ( 13 years, practical) & 1428 & 37.5 & 668 & $34 \cdot 3$ & 760 & $40 \cdot 7$ \\
\hline Short higher (13-14 years) & 290 & 7.6 & 146 & 7.5 & 144 & 7.7 \\
\hline Medium higher (15-16 years) & 832 & $21 \cdot 8$ & 495 & $25 \cdot 4$ & 337 & $18 \cdot 1$ \\
\hline Long higher ( $\geq 17$ years) & 461 & $12 \cdot 1$ & 207 & $10 \cdot 6$ & 254 & $10 \cdot 6$ \\
\hline \multicolumn{7}{|l|}{ Weight statust ( $n 3575), n$ and \% } \\
\hline Underweight $\left(\mathrm{BMI}<18.5 \mathrm{~kg} / \mathrm{m}^{2}\right)$ & 80 & $2 \cdot 2$ & 47 & $2 \cdot 6$ & 33 & 1.9 \\
\hline Normal $\left(18.5 \mathrm{~kg} / \mathrm{m}^{2} \leq \mathrm{BMl}<25 \mathrm{~kg} / \mathrm{m}^{2}\right)$ & 1801 & $50 \cdot 4$ & 987 & $54 \cdot 7$ & 814 & $45 \cdot 9$ \\
\hline Overweight $\left(25 \mathrm{~kg} / \mathrm{m}^{2} \leq \mathrm{BMI}<30 \mathrm{~kg} / \mathrm{m}^{2}\right)$ & 1204 & 33.7 & 546 & $30 \cdot 3$ & 658 & $37 \cdot 1$ \\
\hline Obese $\left(\mathrm{BMI} \geq 30 \mathrm{~kg} / \mathrm{m}^{2}\right)$ & 490 & $13 \cdot 7$ & 223 & $12 \cdot 4$ & 267 & $15 \cdot 1$ \\
\hline
\end{tabular}

*Highest completed education. Adolescents undertaking upper secondary school education are excluded $(n 115)$. For children $(<15$ years), the educational level of the parent who filled in the interview form is given.

†Based on measured weight and height. International Obesity Task Force BMl cut-offs were used to determine weight status in children. 
Table 2 Physical activity and dietary intake on weekdays (Monday-Thursday), Friday, Saturday and Sunday for the whole study population of 4-75-year-old Danes (Danish National Survey of Diet and Physical Activity 2011-2013)

\begin{tabular}{|c|c|c|c|c|c|c|c|c|}
\hline & \multicolumn{2}{|c|}{ Monday-Thursday } & \multicolumn{2}{|c|}{ Friday } & \multicolumn{2}{|c|}{ Saturday } & \multicolumn{2}{|c|}{ Sunday } \\
\hline & Mean/Prob. & $95 \% \mathrm{Cl}$ & Mean/Prob. & $95 \% \mathrm{Cl}$ & Mean/Prob. & $95 \% \mathrm{Cl}$ & Mean/Prob. & $95 \% \mathrm{Cl}$ \\
\hline \multicolumn{9}{|l|}{ Physical activity* } \\
\hline Steps/d & $8767^{\mathrm{a}}$ & 8645,8891 & $8965^{a}$ & 8804,9127 & $7861^{\mathrm{b}}$ & 7710,8013 & $7303^{c}$ & 7156,7452 \\
\hline Cadence (steps/min) & $10 \cdot 1^{\mathrm{a}}$ & $10 \cdot 0,10 \cdot 3$ & $10 \cdot 0^{\mathrm{a}}$ & $9 \cdot 8,10 \cdot 2$ & $9 \cdot 3^{\mathrm{b}}$ & $9 \cdot 2,9.5$ & $9 \cdot 2^{\mathrm{b}}$ & $9 \cdot 0,9 \cdot 4$ \\
\hline Cycling-adjusted (steps/d) & $9926^{\mathrm{a}}$ & 9784,10069 & $10007^{\mathrm{a}}$ & 9821,10194 & $8525^{b}$ & 8353,8698 & $7902^{c}$ & 7735,8072 \\
\hline Cycling-adjusted cadence (steps/min) & $11.5^{\mathrm{a}}$ & $11 \cdot 3,11 \cdot 6$ & $11 \cdot 2^{\mathrm{a}}$ & $11 \cdot 0,11.4$ & $10 \cdot 1^{\mathrm{b}}$ & $9.9,10.3$ & $10 \cdot 0^{\mathrm{b}}$ & $9 \cdot 8,10 \cdot 2$ \\
\hline \multicolumn{9}{|l|}{ Energy and macronutrients* } \\
\hline Energy (MJ) & $9 \cdot 0^{\mathrm{a}}$ & $8 \cdot 9,9 \cdot 1$ & $10 \cdot 2^{\mathrm{b}}$ & $10 \cdot 1,10 \cdot 3$ & $10 \cdot 7^{\mathrm{c}}$ & $10 \cdot 6,10 \cdot 8$ & $9 \cdot 6^{d}$ & $9 \cdot 5,9 \cdot 7$ \\
\hline Fat $(\mathrm{E} \%)$ & $36 \cdot 4^{\mathrm{a}}$ & $36 \cdot 2,36 \cdot 6$ & $36 \cdot 4^{\mathrm{a}}$ & $36 \cdot 1,36 \cdot 6$ & $37 \cdot 5^{\mathrm{b}}$ & $37 \cdot 3,37 \cdot 8$ & $37 \cdot 7^{\mathrm{b}}$ & $37.5,38.0$ \\
\hline Saturated fat (E\%) & $14 \cdot 4^{\mathrm{a}}$ & $14 \cdot 3,14.5$ & $14.5^{\mathrm{a}}$ & $14 \cdot 4,14 \cdot 6$ & $15 \cdot 2^{\mathrm{b}}$ & $15 \cdot 0,15 \cdot 3$ & $15 \cdot 3^{\mathrm{b}}$ & $15 \cdot 2,15 \cdot 4$ \\
\hline Carbohydrates (E\%) & $47 \cdot 2^{\mathrm{a}}$ & $47 \cdot 0,47 \cdot 4$ & $48 \cdot 0^{\mathrm{b}}$ & $47 \cdot 7,48 \cdot 2$ & $46 \cdot 8^{\mathrm{ac}}$ & $46 \cdot 6,47 \cdot 1$ & $46 \cdot 5^{\mathrm{C}}$ & $46 \cdot 2,46 \cdot 8$ \\
\hline Added sugar (E\%) & $8 \cdot 0^{\mathrm{a}}$ & $7 \cdot 8,8 \cdot 2$ & $10 \cdot 1^{b c}$ & $9.9,10.4$ & $10 \cdot 7^{b}$ & $10 \cdot 5,10 \cdot 9$ & $9 \cdot 6^{\mathrm{C}}$ & $9.4,9.9$ \\
\hline Protein $(\mathrm{E} \%)$ & $16 \cdot 4^{\mathrm{a}}$ & $16 \cdot 3,16 \cdot 5$ & $15 \cdot 6^{\mathrm{b}}$ & $15 \cdot 5,15 \cdot 8$ & $15 \cdot 6^{\mathrm{b}}$ & $15 \cdot 5,15 \cdot 8$ & $15 \cdot 8^{\mathrm{b}}$ & $15 \cdot 7,15 \cdot 9$ \\
\hline Fibre (g/10 MJ) & $26 \cdot 1^{\mathrm{a}}$ & $25 \cdot 8,26 \cdot 3$ & $22 \cdot 5^{\mathrm{b}}$ & $22 \cdot 3,22 \cdot 8$ & $20 \cdot 3^{c}$ & $20 \cdot 1,20 \cdot 6$ & $21 \cdot 8^{\mathrm{d}}$ & $21 \cdot 5,22 \cdot 1$ \\
\hline \multicolumn{9}{|l|}{ Energy density (kJ/100 g) } \\
\hline Solids & $724^{\mathrm{a}}$ & 719,729 & $788^{b}$ & 781,794 & $823^{c}$ & 817,830 & $816^{c}$ & 809,822 \\
\hline Liquids & $55^{a}$ & 54,56 & $70^{\mathrm{b}}$ & 68,71 & $80^{c}$ & 79,82 & $68^{\mathrm{b}}$ & 66,70 \\
\hline \multicolumn{9}{|l|}{ Foods and beverages ${ }^{*}, \dagger$} \\
\hline \multicolumn{9}{|l|}{ Vegetables } \\
\hline Prob. $\neq$ & $0.99^{a}$ & $0.98,0.99$ & $0.99^{a}$ & $0.98,0.99$ & $0.99^{a}$ & $0.98,0.99$ & $0.99^{a}$ & $0.98,0.99$ \\
\hline $\mathrm{g} / 10 \mathrm{MJ}$ & $155^{\mathrm{a}}$ & 152,159 & $133^{b}$ & 128,138 & $117^{c}$ & 112,121 & $119^{c}$ & 114,123 \\
\hline \multicolumn{9}{|l|}{ Fruit } \\
\hline Prob.§ & $0.97^{a}$ & $0.96,0.97$ & $0.96^{b}$ & $0.95,0.96$ & $0.95^{\mathrm{b}}$ & $0.95,0.96$ & $0.94^{\mathrm{b}}$ & $0.93,0.95$ \\
\hline $\mathrm{g} / 10 \mathrm{MJ}$ & $137^{a}$ & 133,142 & $104^{\mathrm{b}}$ & 99,109 & $88^{c}$ & 84,92 & $99^{b}$ & 94,103 \\
\hline \multicolumn{9}{|l|}{ Red meat } \\
\hline Prob.§ & $0.94^{a}$ & $0.94,0.95$ & $0.95^{\mathrm{a}}$ & $0.94,0.95$ & $0.95^{a}$ & $0.94,0.95$ & $0.93^{a}$ & $0.92,0.94$ \\
\hline $\mathrm{g} / 10 \mathrm{MJ}$ & $104^{a}$ & 102,106 & $97^{\mathrm{b}}$ & 94,100 & $108^{a}$ & 104,111 & $105^{a}$ & 102,109 \\
\hline \multicolumn{9}{|l|}{ Fish } \\
\hline Prob.§ & $0.41^{\mathrm{a}}$ & $0.40,0.42$ & $0.41^{a, b}$ & $0.39,0.43$ & $0.42^{a, b}$ & $0.40,0.44$ & $0 \cdot 37^{b}$ & $0.36,0.39$ \\
\hline $\mathrm{g} / 10 \mathrm{MJ}$ & $41^{\mathrm{a}}$ & 39,42 & $40^{\mathrm{a}}$ & 37,43 & $39^{a}$ & 37,42 & $42^{\mathrm{a}}$ & 40,45 \\
\hline \multicolumn{9}{|l|}{ Fast food } \\
\hline Prob.\| & $0 \cdot 23^{a}$ & $0.22,0.23$ & $0.30^{b}$ & $0.29,0.32$ & $0.29^{b}$ & $0.28,0.31$ & $0.27^{b}$ & $0.25,0.28$ \\
\hline $\mathrm{g} / 10 \mathrm{MJ}$ & $196^{a}$ & 190,201 & $197^{a}$ & 189,206 & $170^{\mathrm{b}}$ & 163,178 & $187^{a, b}$ & 179,196 \\
\hline \multicolumn{9}{|l|}{ Wholegrain products } \\
\hline Prob.§ & $0.93^{\mathrm{a}}$ & $0.93,0.94$ & $0.92^{\mathrm{a}}$ & $0.91,0.93$ & $0.88^{b}$ & $0.87,0.89$ & $0.88^{b}$ & $0.86,0.89$ \\
\hline $\mathrm{g} / 10 \mathrm{MJ}$ & $120^{\mathrm{a}}$ & 118,122 & $100^{\mathrm{b}}$ & 98,103 & $93^{c}$ & 91, 95 & $101^{\mathrm{b}}$ & 99,104 \\
\hline \multicolumn{9}{|l|}{ Discretionary foods } \\
\hline Prob.§ & $0 \cdot 77^{\mathrm{a}}$ & $0.76,0.78$ & $0.87^{\mathrm{b}, \mathrm{c}}$ & $0.86,0.88$ & $0 \cdot 88^{b}$ & $0.88,0.90$ & $0 \cdot 85^{c}$ & $0.84,0.86$ \\
\hline $\mathrm{g} / 10 \mathrm{MJ}$ & $69^{a}$ & 68,71 & $91^{\mathrm{b}}$ & 88,94 & $96^{b}$ & 93,99 & $90^{\mathrm{b}}$ & 87,93 \\
\hline \multicolumn{9}{|l|}{ Sugar-sweetened beverages } \\
\hline Prob.§ & $0.12^{\mathrm{a}}$ & $0.11,0.13$ & $0 \cdot 22^{b, c}$ & $0.21,0.24$ & $0.25^{\mathrm{b}}$ & $0.23,0.27$ & $0.19^{c}$ & $0.17,0.21$ \\
\hline $\mathrm{g} / 10 \mathrm{MJ}$ & $399^{\mathrm{a}}$ & 389,409 & $392^{\mathrm{a}}$ & 379,407 & $413^{\mathrm{a}}$ & 399,427 & $401^{\mathrm{a}}$ & 387,416 \\
\hline
\end{tabular}




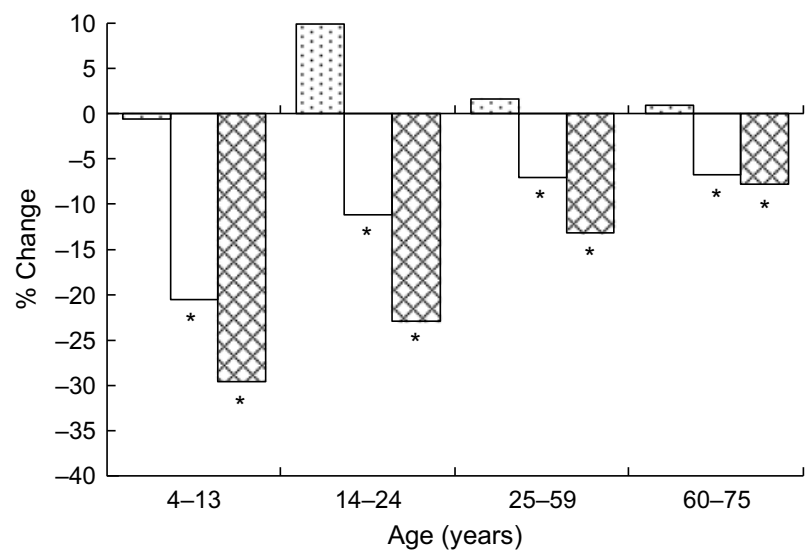

Fig. 1 Differences in pedometer-determined steps counts between weekdays (Monday-Thursday) and Friday (B), Saturday ( $\square$ ) and Sunday (区) according to age group. Data (from the Danish National Survey of Diet and Physical Activity 20112013) are presented as relative differences (percentage) from Monday-Thursday and are based on means estimated from mixed linear models (estimated means and $95 \% \mathrm{Cl}$ are presented in the online supplementary material, Supplemental Table S2). ${ }^{*}$ indicates significant difference in mean compared with Monday-Thursday $(P<0.01)$

Overall, results remained the same when removing under-reporters $(13.4 \%)$ and over-reporters (1.0 \%) from the analyses (data not shown).

\section{Discussion}

As hypothesized, dietary intake and PA were found to fluctuate during the week in this large representative sample of Danes, with weekend days displaying lower dietary quality and less PA compared with weekdays. Saturday displayed in general the poorest dietary quality, while Sunday was the least active day of the week. In terms of dietary intake, Friday resembled a weekend day, while it resembled a weekday in terms of PA. Overall, similar patterns were observed across genders and age groups, although the differences in diet and PA between weekdays and weekend days were most pronounced among children and relatively modest among the elderly population.

Previous studies investigating weekly variation in dietary intake and PA have generally found less healthy behaviour during the weekend. Larger intakes of total energy, fat, added sugar, different discretionary foods and alcohol have consistently been observed during the weekend in studies on Western populations ${ }^{(12-17,43,47-54)}$. However, the increase in total energy intake during weekend days, compared with weekdays, observed in the present study was larger than demonstrated in other large-scale, national studies ${ }^{(13,15-17)}$. In agreement with our findings, previous studies using pedometry or accelerometery have consistently found lower PA level during weekends compared with weekdays in both adults and children $^{(11,19-24,55-63)}$; however, most studies are based on 
(a)

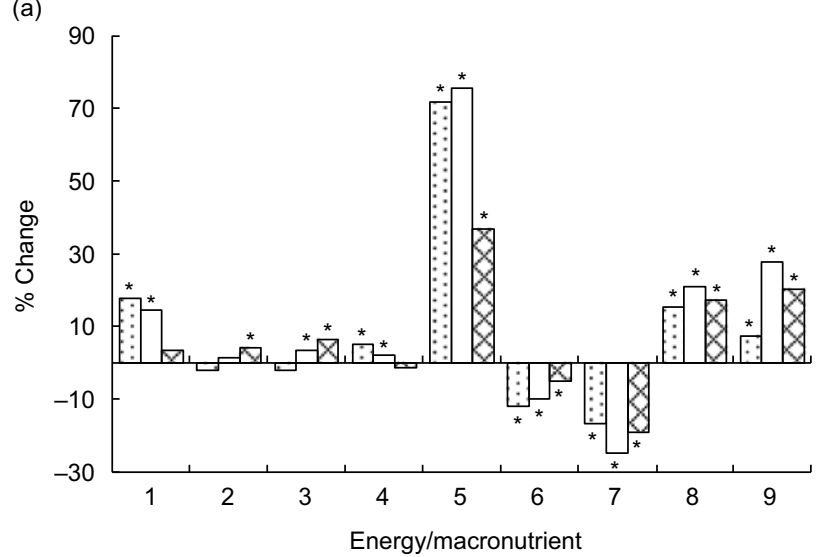

(c)

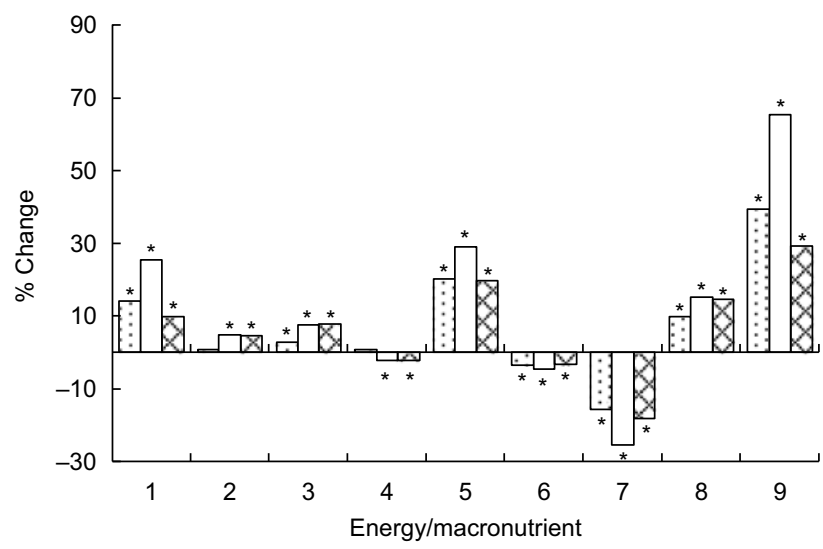

(b)

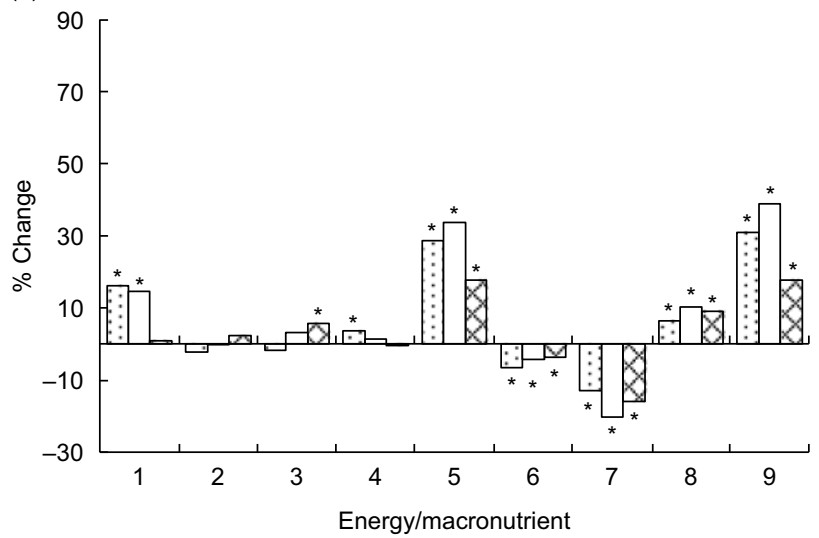

(d)

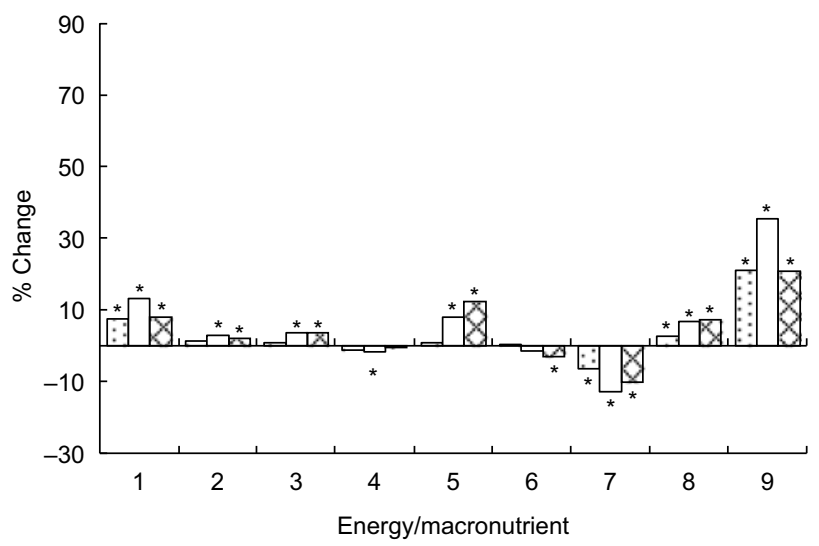

Fig. 2 Differences in energy and macronutrient intakes (1, energy (MJ/d); 2, fat (percentage of total energy intake; $E \%) ; 3$, saturated

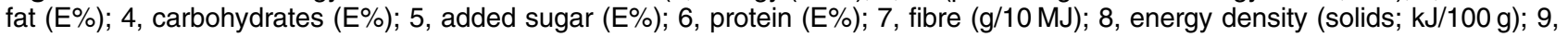

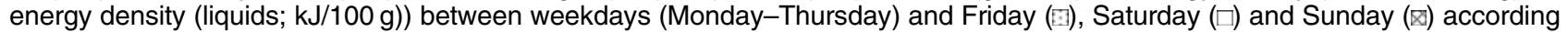
to age group: (a) 4-13 years; (b) 14-24 years; (c) 25-59 years; and (d) 60-75 years. Data (from the Danish National Survey of Diet and Physical Activity 2011-2013) are presented as relative differences (percentage) from Monday-Thursday and are based on means estimated from mixed linear models (estimated means and $95 \% \mathrm{Cl}$ are presented in the online supplementary material, Supplemental Table S5). * indicates significant difference in mean compared with Monday-Thursday $(P<0.01)$

specific populations and narrow age spans. A more detailed summary of previous research on weekly variation in dietary intake and PA can be found in the online supplementary material, Supplemental Tables S7 and S8 and supplementary literature review.

A rationale for the existence of distinct temporally conditioned behavioural patterns, as observed in the present study, could be provided by the fact that human behaviour during weekdays is highly structured and generally dictated by time spent at work/in school ${ }^{(64)}$, and many health promotion initiatives target the weekdays. A change in daily structures during the weekend is likely to have consequences for habitual behaviours like eating and PA. Friday is a transition day between the week and the weekend, with the first half of the day being lived like a weekday and the second half like a weekend day, explaining the observed Friday PA behaviour, which resembles weekdays, and the observed Friday dietary intake behaviour, which resembles weekends. Some of the observed weekly variation in dietary intake may arise from differences in social, environmental and contextual factors of food intake during weekdays and weekend days. De Castro demonstrated that meal sizes during weekends were larger, meal duration was longer, and meals were ingested later and in the company of more people $\mathrm{e}^{(47,65,66)}$. The observed decrease in PA during the weekend could be related to a difference in leisure activities and increased sedentary activities, for instance screen time, as indicated in previous studies ${ }^{(11,67,68)}$.

Only a few other studies have included analysis of weekly variation in different age strata, showing that weekly variation in dietary intake is smaller in elderly compared with younger adults ${ }^{(13,14,17,65)}$. However, children have been found to have smaller weekly variation compared with adults ${ }^{(16,17)}$. In the present analysis, children were the main drivers of the weekly variation of added sugar, sugar-sweetened beverages, discretionary foods and step counts. Children and teens may display the most distinct weekly patterns because their weekdays are highly structured and influenced by time spent at school, while adults' 
(a)

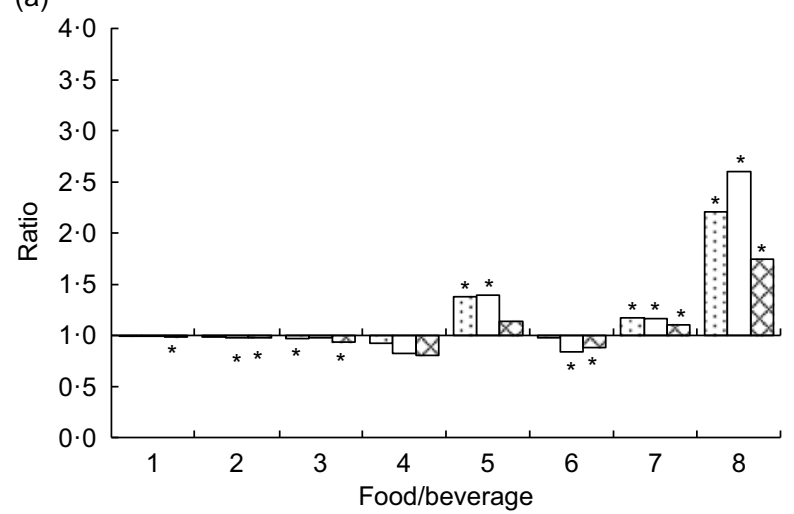

(b)

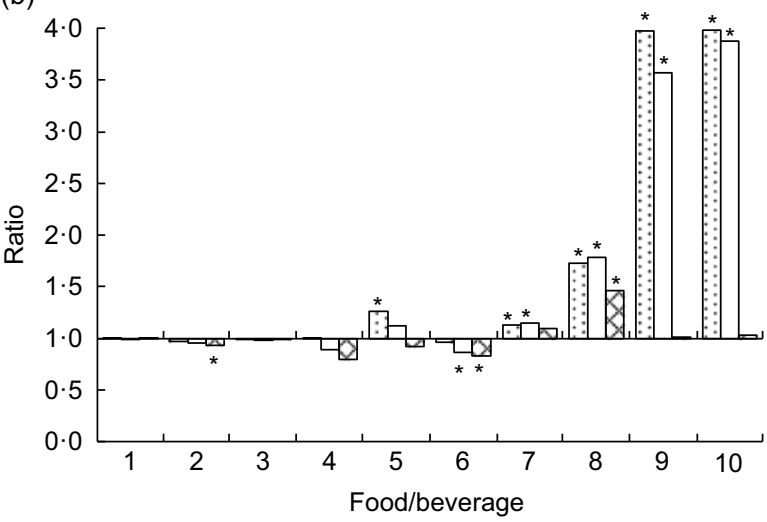

(c)

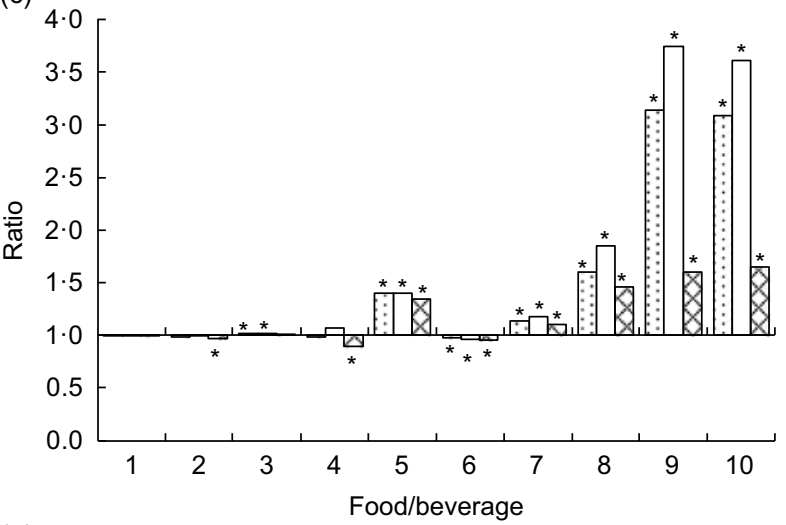

(d)

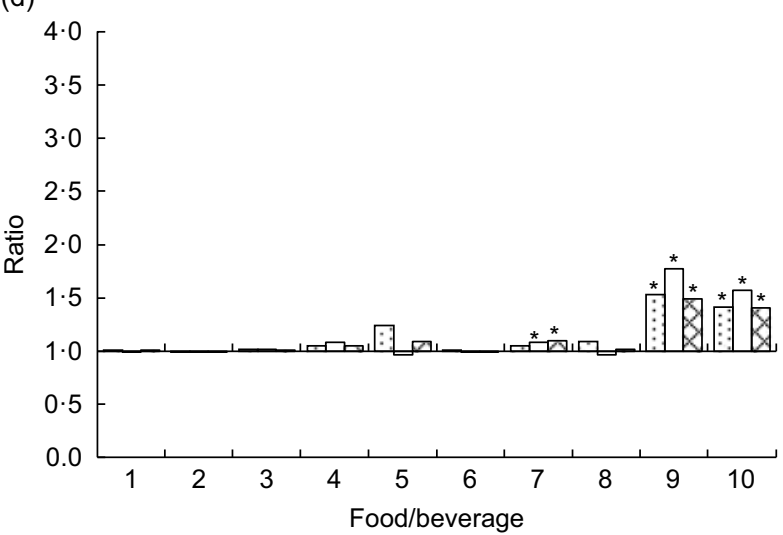

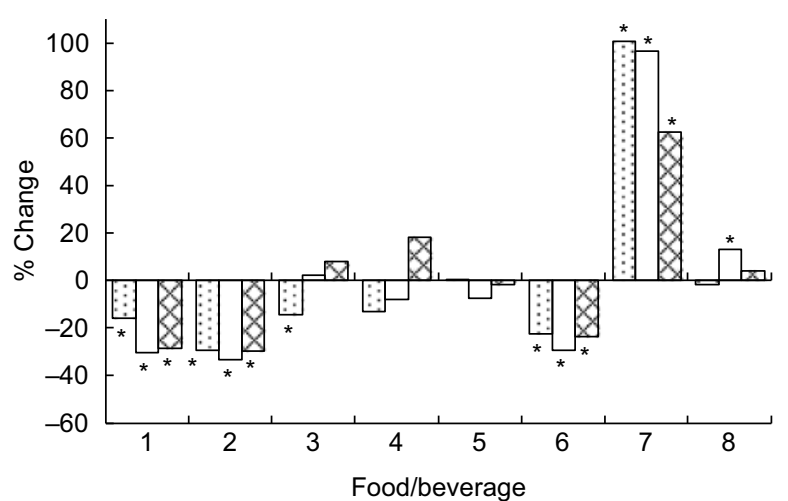
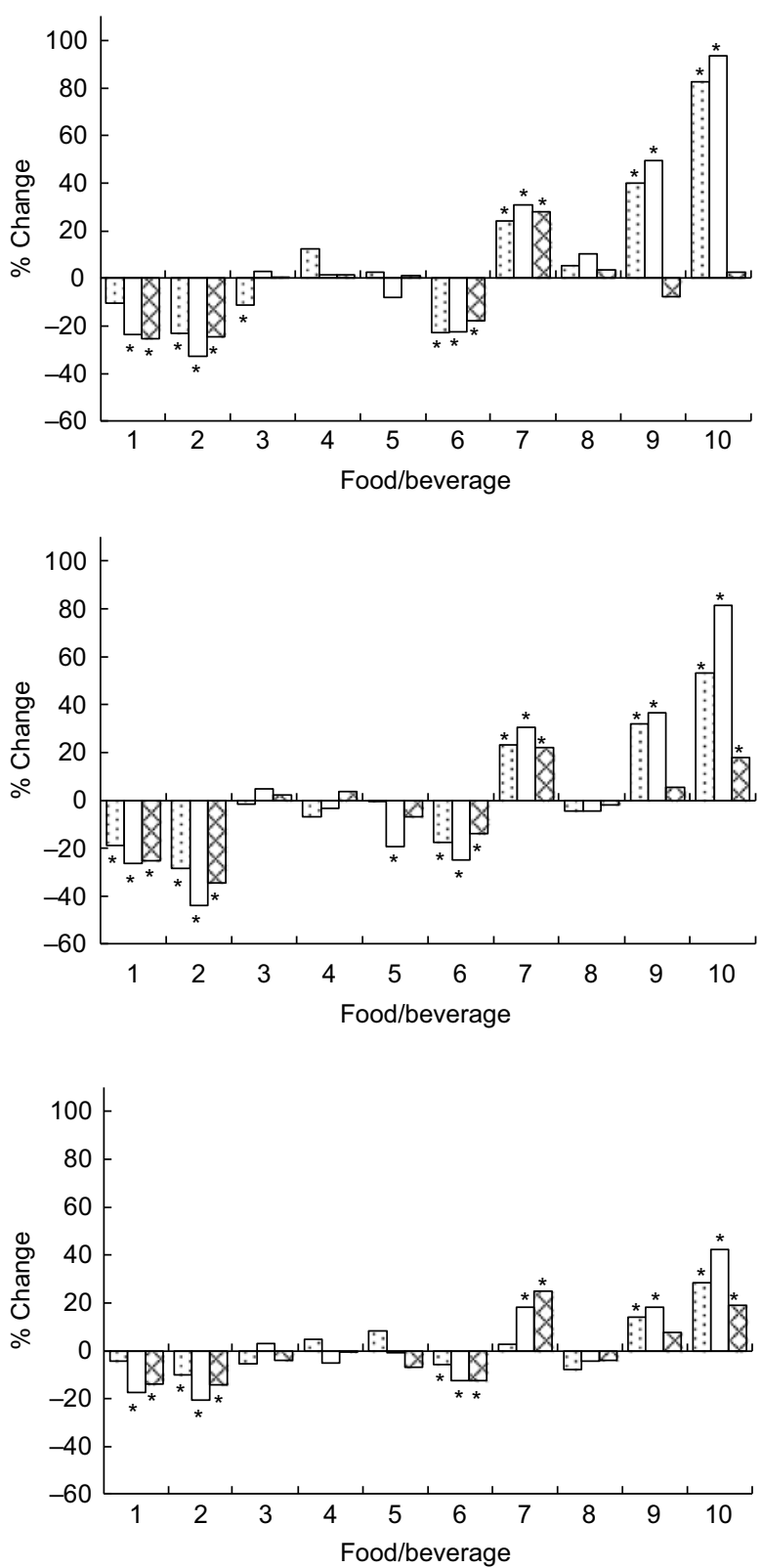

Fig. 3 Food and beverage consumption (1, vegetables; 2, fruit; 3, red meat; 4, fish; 5, fast food; 6, wholegrain products; 7, discretionary

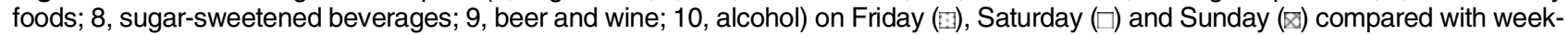
days (Monday-Thursday) according to age group: (a) 4-13 years; (b) 14-24 years; (c) 25-59 years; and (d) 60-75 years. Data (from the Danish National Survey of Diet and Physical Activity 2011-2013) are presented as ratios of the probability of consumption (left column) with Monday-Thursday as reference ( $>1$ indicates higher probability of consumption on weekend day) and as percentage difference in the amounts consumed compared with Monday-Thursday (right column). Data are based on probabilities and means estimated from mixed logistic and linear regression models (probabilities, means and $95 \% \mathrm{Cl}$ are presented in in the online supplementary material, Supplemental Table S6). * indicates significant difference in probability or mean compared with Monday-Thursday $(P<0.01)$. Tests are performed on log-odds scale in logistic regression and on Box-Cox transformed models in linear regression 
behaviour may be subject to additional complexity posed by different work routines and preferences. Among older adults, retirement brings an obvious change to the structure of the week and is a likely determinant of a lesser day-ofthe-week effect in free-living elderly. Children's dietary habits are also subject to parental influence ${ }^{(69)}$. A study of Danish parents' motives for giving their children sugar-rich foods found that parents try to limit children's sugar intake during weekdays and as a consequence sugar-rich foods are 'reserved' for the weekend ${ }^{(70)}$.

Present findings pinpoint weekends as the time of the week when physical inactivity and unfavourable dietary behaviour dominate, and should be targeted by public health interventions. An evaluation of potential long-term adverse health effects of the observed weekly variation in diet and activity would be important for assessing the public health relevance of such patterns, especially the potential contribution to overweight/obesity and related co-morbidities. Acute effects of weekend health behaviour have been observed for different blood markers of metabolic health in Danish populations ${ }^{(25,26)}$. These studies demonstrated that TAG, leptin and homeostatic model assessment of insulin resistance were highest immediately after the weekend and lowered gradually during weekdays, whereas ghrelin increased ${ }^{(25)}$, and the effects were especially large among children and adolescents ${ }^{(26)}$. Plausible contributors to such changes in blood markers could be the components of dietary intake and PA that displayed substantial weekly variation in the present study.

Measurement of both dietary intake and PA in the same individuals allows for consideration of the combined effect of both sides of the energy balance equation: energy intake and energy expenditure. Energy intake increased by $7-20 \%$ on Friday and weekend days in the present study. On a population level there is no indication of compensatory increased energy expenditure by PA, since step counts per day decreased by $10-17 \%$ on Saturday and Sunday, and therefore positive energy balance is a concern. Few studies have investigated the impacts of weekly variation in health behaviour on long-term health outcomes or weight control, but weekly weight fluctuations have been observed, indicating a small weight increase during weekends ${ }^{(27,28)}$. A positive energy balance during the weekend, without compensation during the weekdays, could have a cumulative effect on body weight in the long term, but such effects remain to be investigated.

The current analysis of both PA and dietary intake in a large, nationally representative sample of individuals from 4 to 75 years of age enables consideration of weekly patterns across the lifespan and is to our knowledge the first of its kind. A particular strength of the present study is the wide array of dietary variables examined, providing a versatile presentation of dietary quality and consumption habits. Furthermore, PA is objectively measured and step counts were expressed as both absolute (per day) and relative to wear-time (per minute), as well as adjusted for cycling, which is important since Danes frequently cycle to work as active transportation ${ }^{(71)}$. That said, other nonambulatory activities, such as weightlifting and swimming, are not captured by pedometers and the volume and/or intensity of such activities could be different in weekdays and weekend days. However, at a population level, nonambulatory activities (apart from cycling) contribute only a little to the total volume of PA in Denmark ${ }^{(29)}$. Previous studies in Danish children and adolescents using accelerometers corroborate our finding of lower PA levels during weekends ${ }^{(11,20)}$, and self-reported activity data in Danish adults indicate further that Sunday is the least active day of the week ${ }^{(72)}$. Another limitation of the study is that the response rate in DANSDA was $54 \%$. This rather low response rate may compromise the representativeness of the sample. Compared with the general Danish population, the study population in DANSDA was approximately representative in terms of gender and age, but individuals with a short education were under-represented ${ }^{(4)}$. In a large study of US adults, individuals with high-school education and below appeared to have a smaller weekly variation for selected variables of dietary intake compared with individuals with college education and above ${ }^{(13)}$. Provided that these patterns can be extended to the Danish population, an overestimation of our findings due to non-response bias cannot be excluded. Furthermore, Monday and Tuesday as starting days for dietary recording were over-represented, while Saturday and Sunday were under-represented. Previous analyses on DANSDA have indicated moderately larger under-reporting of energy intake on the first day (experimenter effect) and the last day (fatigue effect) of recording ${ }^{(32)}$, which may give rise to an underestimated energy intake on weekdays due to relatively higher occurrence of these days as start and end days. Finally, underreporting of dietary intake is inevitably present and imprecision of estimates is inherent, but pose a threat to the legitimacy of the observed weekly patterns only if the misreporting and imprecision are differential with respect to weekday. A higher energy intake at weekends could provoke a larger absolute under-reporting for weekends but is unlikely a substantial source of error, since relative under-reporting is likely to be present on all days of the week and sensitivity analysis with and without misreporters showed similar results. Further, a tendency towards a selective under-reporting of energy-dense, high-sugar and highfat foods has been documented ${ }^{(73,74)}$, but such misreporting would, if anything, give rise to an underestimation of the observed weekday-weekend difference, since these types of foods are more commonly consumed at weekends.

\section{Conclusion}

In conclusion, results of the present study indicate that dietary intake and PA of Danes fluctuate substantially during the week, with weekend days having consistently 
lower dietary quality and less PA compared with weekdays. The weekly variation appears especially large among children and modest among the elderly population. Present findings prompt the question whether the large variation could be deconstructed and health behaviour in the weekend improved in an effort to improve public health. This effort should primarily target children and adolescents and their parents to combat the large weekly differences observed and to impact long-term behaviour. Additionally, present findings suggest that proportional sampling of weekdays and weekend days is important when monitoring average diet and PA. Finally, the potential long-term implications of weekly variation on weight management and development of non-communicable diseases need to be explored to enhance understanding of the public health impacts of substantial weekly rhythms in health behaviour.

\section{Acknowledgements}

Acknowledgements: The authors are grateful to data warehouse manager Karsten Kørup and senior advisor Tue Christensen for contributions to data processing in DANSDA and provision of data in the present study. Financial support: This research received no specific grant from any funding agency in the public, commercial or not-for-profit sectors. Conflict of interest: None. Authorship: M.N., M.F.H., J.M. and A.B.-J. designed the research and formulated the research question; M.N. performed the statistical analysis; C.R. provided statistical counselling; M.N. and M.F.H. wrote the manuscript; J.M. and A.B.-J. were responsible for the design and collection of data in the Danish National Survey of Dietary Habits and Physical Activity; all authors contributed to the discussion of analyses, critically reviewed the manuscript and approved the final manuscript. Ethics of buman subject participation: This study was conducted according to the guidelines laid down in the Declaration of Helsinki and approved by the Danish Data Protection Agency. Verbal informed consent was obtained from all participants. The Danish National Committee on Health Research Ethics reviewed the study protocol and all procedures involving research study participants and concluded that DANSDA did not require approval by this authority according to Danish law.

\section{Supplementary material}

To view supplementary material for this article, please visit https://doi.org/10.1017/S1368980019003707

\section{References}

1. Abarca-Gómez L, Abdeen ZA, Hamid ZA et al. (2017) Worldwide trends in body-mass index, underweight, over- weight, and obesity from 1975 to 2016: a pooled analysis of 2416 population-based measurement studies in 128.9 million children, adolescents, and adults. Lancet 390, 2627-2642.

2. World Health Organization (2018) European Health Report 2018. Copenhagen: WHO Regional Office for Europe.

3. World Health Organization (2018) Fact sheet: Obesity and overweight. http://www.who.int/en/news-room/fact-sheets/ detail/obesity-and-overweight (accessed May 2018).

4. Pedersen AN, Christensen T, Matthiessen J et al. (2015) Danskernes kostvaner 2011-2013. Hovedresultater (Dietary Habits in Denmark 2011-2013. Main Results). Søborg: National Food Institute, Technical University of Denmark.

5. World Health Organization (2003) Diet, Nutrition and the Prevention of Chronic Diseases. Joint WHO/FAO Expert Consultation. WHO Technical Report Series no. 916. Geneva: WHO.

6. Hooper L, Martin N, Abdelhamid A et al. (2015) Reduction in saturated fat intake for cardiovascular disease. Cochrane Database Syst Rev issue 6, CD011737.

7. Te Morenga L, Mallard S \& Mann J (2013) Dietary sugars and body weight: systematic review and meta-analyses of randomised controlled trials and cohort studies. BMJ 346, e7492.

8. Schwab U, Lauritzen L, Tholstrup T et al. (2014) Effect of the amount and type of dietary fat on cardiometabolic risk factors and risk of developing type 2 diabetes, cardiovascular diseases, and cancer: a systematic review. Food Nutr Res $\mathbf{5 8}$, 25145 .

9. Sundhedsstyrelsen (2018) Danskernes Sundhed: Den Nationale Sundhedsprofil 2017 (Health of the Danes: The National Health Profile 2017). Copenhagen: Danish Health Authority.

10. Matthiessen J, Andersen LF, Barbieri HE et al. (2016) The Nordic Monitoring System 2011-2014: Status and Development of Diet, Physical Activity, Smoking, Alcohol and Overweight. Copenhagen: Nordic Council of Ministers.

11. Hjorth MF, Chaput J-P, Michaelsen K et al. (2013) Seasonal variation in objectively measured physical activity, sedentary time, cardio-respiratory fitness and sleep duration among 8-11 year-old Danish children: a repeated-measures study. BMC Public Health 13, 808.

12. Rothausen BW, Matthiessen J, Hoppe C et al. (2012) Differences in Danish children's diet quality on weekdays $v$. weekend days. Public Health Nutr 15, 1653-1660.

13. An R (2016) Weekend-weekday differences in diet among US adults, 2003-2012. Ann Epidemiol 26, 57-65.

14. Thompson FE, Larkin FA \& Brown MB (1986) Weekendweekday differences in reported dietary intake: the nationwide food consumption survey, 1977-78. Nutr Res 6, 647-662.

15. Yang PH, Black JL, Barr SI et al. (2014) Examining differences in nutrient intake and dietary quality on weekdays versus weekend days in Canada. Appl Physiol Nutr Metab 39, 1413-1417.

16. Monteiro LS, Hassan BK, Estima CCP et al. (2017) Food consumption according to the days of the week - National Food Survey, 2008-2009. Rev Saude Publica 51, 93.

17. Haines PS, Hama MY, Guilkey DK et al. (2003) Weekend eating in the United States is linked with greater energy, fat, and alcohol intake. Obes Res 11, 945-949.

18. Rockell JE, Parnell WR, Wilson NC et al. (2011) Nutrients and foods consumed by New Zealand children on schooldays and non-schooldays. Public Health Nutr 14, 203-208.

19. Refinetti R, Sani M, Jean-Louis G et al. (2015) Evidence for daily and weekly rhythmicity but not lunar or seasonal rhythmicity of physical activity in a large cohort of individuals from five different countries. Ann Med 47, 530-537.

20. Kristensen PL, Korsholm L, Møller N et al. (2008) Sources of variation in habitual physical activity of children and adolescents: the European youth heart study. Scand J Med Sci Sports 18, 298-308. 
21. Nilsson A, Anderssen SA, Andersen LB et al. (2009) Betweenand within-day variability in physical activity and inactivity in 9- and 15-year-old European children. Scand JMed Sci Sports 19, 10-18.

22. Comte M, Hobin E, Majumdar SR et al. (2013) Patterns of weekday and weekend physical activity in youth in 2 Canadian provinces. Appl Physiol Nutr Metab 38, 115-119.

23. Treuth MS, Catellier DJ, Schmitz KH et al. (2007) Weekend and weekday patterns of physical activity in overweight and normal-weight adolescent girls. Obesity (Silver Spring) 15, 1782-1788.

24. Rowlands AV, Pilgrim EL \& Eston RG (2008) Patterns of habitual activity across weekdays and weekend days in 9-11-year-old children. Prev Med 46, 317-324.

25. Hjorth MF, Damsgaard CT, Michaelsen KF et al. (2015) Markers of metabolic health in children differ between weekdays - the result of unhealthier weekend behavior. Obesity (Silver Spring) 23, 733-736.

26. JaskolowskiJ, Ritz C, Sjodin A et al. (2017) Weekday variation in triglyceride concentrations in 1.8 million blood samples. J Lipid Res 58, 1204-1213.

27. Racette SB, Weiss EP, Schechtman KB et al. (2008) Influence of weekend lifestyle patterns on body weight. Obesity (Silver Spring) 16, 1826-1830.

28. Orsama AL, Mattila E, Ermes M et al. (2014) Weight rhythms: weight increases during weekends and decreases during weekdays. Obes Facts 7, 36-47.

29. Matthiessen J, Andersen EW, Raustorp A et al. (2015) Reduction in pedometer-determined physical activity in the adult Danish population from 2007 to 2012. Scand J Public Health 43, 525-533.

30. Pedersen CB (2011) The Danish civil registration system. Scand J Public Health 39, 22-25.

31. Knudsen VK, Gille MB, Nielsen TH et al. (2011) Relative validity of the pre-coded food diary used in the Danish National Survey of Diet and Physical Activity. Public Health Nutr 14, 2110-2116.

32. Biltoft-Jensen A, Matthiessen J, Rasmussen LB et al. (2009) Validation of the Danish 7-day pre-coded food diary among adults: energy intake $v$. energy expenditure and recording length. Br J Nutr 102, 1838-1846.

33. Rothausen B, Matthiessen J, Groth M et al. (2012) Comparison of estimated energy intake from $2 \times 24$-hour recalls and a seven-day food record with objective measurements of energy expenditure in children. Food Nutr Res 56, 12221.

34. Black AE (2000) Critical evaluation of energy intake using the Goldberg cut-off for energy intake-basal metabolic rate. A practical guide to its calculation, use and limitations. Int J Obes Relat Metab Disord 24, 1119-1130.

35. Goldberg G, Black A, Jebb S et al. (1991) Critical evaluation of energy intake data using fundamental principles of energy physiology: 1 . Derivation of cut-off limits to identify underrecording. Eur J Clin Nutr 45, 569-581.

36. European Food Safety Authority (2014) Guidance on the EU Menu methodology. EFSA J 12, 3944.

37. Schofield W (1985) Predicting basal metabolic rate, new standards and review of previous work. Hum Nutr Clin Nutr 39, 5-41.

38. Mejborn H, Biltoft-Jensen A, Trolle E et al. (2008) Fuldkorn: Definition og vidensgrundlag for anbefaling af fuldkornsindtag $i$ Danmark (Whole Grain: Definition and Knowledge Base for the Recommended Intake of Whole Grain in Denmark). Søborg: National Food Institute, Technical University of Denmark.

39. Tudor-Locke C, Lind KA, Reis JP et al. (2004) A preliminary evaluation of a pedometer-assessed physical activity selfmonitoring survey. Field Methods 16, 422-438.

40. Tudor-Locke C, Mire EF, Dentro KN et al. (2015) A model for presenting accelerometer paradata in large studies: ISCOLE. Int J Behav Nutr Phys Act 12, 52.
41. Tudor-Locke C, Bassett DR, Shipe MF et al. (2011) Pedometry methods for assessing free-living adults. J Phys Act Health $\mathbf{8}$, 445-453.

42. Cole TJ, Bellizzi MC, Flegal KM et al. (2000) Establishing a standard definition for child overweight and obesity worldwide: international survey. BMJ 320, 1240-1243.

43. Jahns L, Conrad Z, Johnson LK et al. (2017) Diet quality is lower and energy intake is higher on weekends compared with weekdays in midlife women: a 1-year cohort study. J Acad Nutr Diet 117, 1080-1086.e1.

44. Lenth RV (2016) Least-squares means: the R package lsmeans. J Stat Softw 69, 1-33.

45. Hothorn T, Bretz F \& Westfall P (2008) Simultaneous inference in general parametric models. Biom $J \mathbf{5 0}$, 346-363.

46. R Core Team (2016) R: A Language and Environment for Statistical Computing, 3.3.2 ed. Vienna: R Foundation for Statistical Computing.

47. de Castro JM (1991) Weekly rhythms of spontaneous nutrient intake and meal pattern of humans. Physiol Behav 50, 729-738

48. Jula A, Seppanen R \& Alanen E (1999) Influence of days of the week on reported food, macronutrient and alcohol intake among an adult population in south western Finland. Eur J Clin Nutr 53, 808-812.

49. Maisey S, Loughridge J, Southon S et al. (1995) Variation in food group and nutrient intake with day of the week in an elderly population. Br J Nutr 73, 359-373.

50. Nansel TR, Lipsky LM, Liu A et al. (2014) Contextual factors are associated with diet quality in youth with type 1 diabetes mellitus. J Acad Nutr Diet 114, 1223-1229.

51. Post B, Kemper HC \& Strom-Van Essen L (1987) Longitudinal changes in nutritional habits of teenagers: differences in intake between schooldays and weekend days. Br J Nutr 57, 161-176.

52. Richard L \& Roberge AG (1982) Comparison of caloric and nutrient intake of adults during week and week-end days. Nutr Res 2, 661-668.

53. Rhodes DG, Cleveland LE, Murayi T et al. (2007) The effect of weekend eating on nutrient intakes and dietary patterns [abstract]. FASEB J 21, 835.832 .

54. Svensson A, Larsson C, Eiben G et al. (2014) European children's sugar intake on weekdays versus weekends: the IDEFICS study. Eur J Clin Nutr 68, 822-828.

55. Brusseau T, Kulinna P, Tudor-Locke C et al. (2011) Children's step counts on weekend, physical education, and nonphysical education days. J Hum Kinet 27, 123-134.

56. Jones R, Brusseau TA, Kulinna PH et al. (2016) Step counts on weekdays, weekends, and during physical education of Navajo high school students. I Racial Ethn Health Disparities 4, 911-915.

57. Duncan MJ, Al-Nakeeb Y, Woodfield L et al. (2007) Pedometer determined physical activity levels in primary school children from central England. Prev Med $\mathbf{4 4}$, 416-420.

58. Behrens TK \& Dinger MK (2003) A preliminary investigation of college students' physical activity patterns. Am J Health Stud 18, 169.

59. Tudor-Locke C, Ham SA, Macera CA et al. (2004) Descriptive epidemiology of pedometer-determined physical activity. Med Sci Sports Exerc 36, 1567-1573.

60. Aibar A, Bois JE, Generelo E et al. (2013) A cross-cultural study of adolescents' physical activity levels in France and Spain. Eur J Sport Sci 13, 551-558.

61. Nader PR, Bradley RH, Houts RM et al. (2008) Moderate-tovigorous physical activity from ages 9 to 15 years. JAMA 300, 295-305.

62. Riddoch CJ, Mattocks C, Deere K et al. (2007) Objective measurement of levels and patterns of physical activity. Arch Dis Child 92, 963-969. 
63. Matthews CE, Ainsworth BE, Thompson RW et al. (2002) Sources of variance in daily physical activity levels as measured by an accelerometer. Med Sci Sports Exerc 34, 1376-1381.

64. McCarthy S (2014) Weekly patterns, diet quality and energy balance. Physiol Behav 134, 55-59.

65. de Castro JM (2002) Age-related changes in the social, psychological, and temporal influences on food intake in free-living, healthy, adult humans. J Gerontol A Biol Sci Med Sci 57, M368-M377.

66. de Castro JM (1991) Social facilitation of the spontaneous meal size of humans occurs on both weekdays and weekends. Physiol Behav 49, 1289-1291.

67. Hart CN, Raynor HA, Osterholt KM et al. (2011) Eating and activity habits of overweight children on weekdays and weekends. Int J Pediatr Obes 6, 467-472.

68. Rey-López JP, Vicente-Rodriguez G, Ortega FB et al. (2010) Sedentary patterns and media availability in European adolescents: the HELENA study. Prev Med 51, 50-55.

69. Taylor JP, Evers S \& McKenna M (2005) Determinants of healthy eating in children and youth. Can J Public Health 96, Suppl. 3, S20-S26.
70. Iversen JD, Matthiessen J, Fagt S et al. (2011) Børns sukkervaner - Undersøgelse af sukkerkulturen blandt børnefamilier med 4-12-årige børn (Children's Sugar Habits - A Study of the Sugar Culture among Families with 4-12-Year-Old Children). Søborg: National Food Institute, Technical University of Denmark.

71. Hallal PC, Andersen LB, Bull FC et al. (2012) Global physical activity levels: surveillance progress, pitfalls, and prospects. Lancet 380, 247-257.

72. Matthiessen J, Rothausen BW, Sørensen MR et al. (2009) Fysisk aktivitet $i$ den voksne danske befolkning 2003-2006 med fokus på anbefalingerne for fysisk aktivitet (Physical Activity in the Danish Adult Population 2003-2006 - With Focus on the Recommendations for Physical Activity). Søborg: National Food Institute, Technical University of Denmark.

73. Rasmussen LB, Matthiessen J, Biltoft-Jensen A et al. (2007) Characteristics of misreporters of dietary intake and physical activity. Public Health Nutr 10, 230-237.

74. Heitmann BL, Lissner L \& Osler M (2000) Do we eat less fat, or just report so? Int J Obes Relat Metab Disord 24, $435-442$. 